\title{
IMPLICAÇÕES DOS DESVIOS CLIMÁTICOS E USO E OCUPAÇÃO DA TERRA EM MANANCIAIS HÍDRICOS: UM ESTUDO DE CASO NA BACIA HIDROGRÁFICA DO CÓRREGO MOEDA, TRÊS LAGOAS/MS
}

\author{
Rafael Brugnolli Medeiros ${ }^{1}$ \\ Weslen Manari Gomes ${ }^{2}$ \\ André Luiz Pinto ${ }^{3}$
}

\begin{abstract}
RESUMO
Esta pesquisa avalia a influencia do uso da terra e desvios climáticos na qualidade das águas de bacias hidrográficas, elegendo como estudo de caso a Bacia Hidrográfica do Córrego Moeda, Três Lagoas/MS, devido à grande expansão agroindustrial verificada neste município. A metodologia consiste em analisar estacionalmente em 2012 parâmetros como: oxigênio dissolvido, pH, turbidez, condutividade elétrica e temperaturas do ar e água, qualificando conforme resolução 357/05 do CONAMA e dados meteorológicos e uso e ocupação da terra da Fibria MS Celulose Ltda. Os resultados apontaram que o ano de 2012, foi seco, em relação à normal, com exceção apenas do outono e que o uso preponderante da bacia, com hortos de eucalipto, que abrangem mais de $57 \%$, alterou a qualidade de suas águas. Sobretudo no Córrego Buriti, que secou completamente, mesmo com o aumento das chuvas na estação da primavera. Como conclusão, elaborou-se algumas sugestões buscando auxiliar em futuros planejamentos, visando a manutenção de seu potencial hídrico para abastecimento não apenas rural, como também de aglomerados urbanos.
\end{abstract}

PALAVRAS-CHAVE: Qualidade das águas, regime climático, uso e ocupação da terra, mananciais hídricos.

\section{IMPLICATIONS OF CLIMATE DEVIATIONS AND USE AND OCCUPATION OF LAND HYDRIC SOURCES: A CASE STUDY IN HYDROGRAPHIC BASIN STREAM MOEDA, TRÊS LAGOAS/MS}

\begin{abstract}
This research evaluates the influence of land use and climate deviations in the quality of hydrographic basins water, electing as a case study the Hydrographic Basin Stream Moeda, Três Lagoas / MS due to the large agroindustrial expansion observed in this municipality. The methodology is to analyze seasonally in 2012 as parameters: dissolved oxygen, $\mathrm{pH}$, turbidity, electrical conductivity and temperature of air and water, qualifying as Resolution 357/05 of CONAMA and meteorological data and land use and occupation of Fibria Celulose Ltda MS. The results showed that the year 2012 was dry compared to normal, except only autumn and that the predominant use of the basin, with gardens of eucalyptus, covering more than $57 \%$, changed the quality of its waters. Mostly in Buriti Stream, which has dried completely, even with the increased rainfall in the spring season. In conclusion, we
\end{abstract}

\footnotetext{
${ }^{1}$ Graduado em Geografia Bacharelado e Bolsista CAPES pelo Programa de Pós-Graduação em Geografia da UFMS/CPTL; rafael_bmedeiros@hotmail.com;

${ }^{2}$ Graduado em Geografia Licenciatura e Mestrando do Programa de Pós-Graduação em Geografia da UFMS/CPTL; weslenmanari@hotmail.com;

${ }^{3}$ Doutor em Geociências e Professor Associado IV da UFMS/CPTL; andre.pinto@ufms.br;
} 
prepared some suggestions seeking auxiliary in future planning, aimed at maintaining its water potential to supply not only rural but also in urban agglomerations.

Keywords: Water quality, climate regime, use and occupation of land, hydric sources.

\section{IMPLICACIONES DE DEFICIENCIAS CLIMÁTICO Y EL USO Y LA OCUPACIÓN DE LA TIERRA EN MANANTIAL HÍDRICO: UN ESTUDIO DE CASO EM CUENCA HIDROGRÁFICA ARROYO MOEDA, TRES LAGOS/MS}

\section{RESUMEN}

Esta investigación evalúa la influencia del uso de la tierra y los cambios climáticos en la calidad del agua de las cuencas hidrográficas, la elección como estudio de caso Cuenca Hidrográfica Arroyo Moeda, Três Lagoas/MS debido a la gran expansión agroindustrial observada en este condado. La metodología consiste en analizar la temporada en 2012 como parámetros: oxígeno disuelto, pH, turbidez, conductividad eléctrica y la temperatura del aire y del agua, la clasificación como la Resolución 357/05 de la CONAMA y los datos meteorológicos y de uso de la tierra y la ocupación de Fibria Celulose Ltda MS. Los resultados mostraron que el año 2012 fue seco en comparación a la normalidad, con la única excepción de la caída y que el uso predominante de la cuenca, con viveros de eucalipto, que cubre más del $57 \%$, alteración de la calidad de sus aguas. Especialmente en el Buriti Arroyo, que se ha secado por completo, incluso con el aumento de las lluvias en la temporada de primavera. En conclusión, hemos preparado algunas sugerencias que buscan ayuda en la planificación del futuro, destinadas a mantener su potencial de agua para abastecer no sólo rural sino también en las zonas urbanas.

Palabras Clave: La calidad del agua, régimen climático, el uso y ocupación de la tierra, las fuentes de agua.

\section{INTRODUÇÃO}

A gestão integrada dos mananciais hídricos se torna imprescindível para a sobrevivência dos ecossistemas e são unidades reguladoras de todo o sistema bacia hidrográfica, deve ser aproveitado de maneira sustentável, beneficiando gerações futuras. Portanto, os estudos em bacias hidrográficas vêm se tornando cada vez mais utilizadas por pesquisadores que buscam, entre diversos motivos, analisar o modo que este ambiente está se comportando diante do avanço das atividades antrópicas. As bacias hidrográficas agregam unidades dos subsistemas, natural, construído, socioeconômico cultural e produtivo, que interagem entre si e com seu entorno.

Dessa forma, todos esses elementos estão correlacionados e a partir do momento que é conhecido suas interações, assim como o peso e importância que cada elemento, suas influências internas e externas exercem sobre o sistema, tornam-se possível propor formas adequadas de uso, ocupação e manejo da terra, minimizando os impactos sobre os recursos hídricos. 


\section{Periódica Eletrânica

Assim sendo, o uso, ocupação e manejo da terra influenciam na dinâmica do escoamento superficial/subterrâneo, definindo diversos parâmetros de resistência às ações dos agentes externos e posteriormente causando os transportes de materiais e sedimentos que interferem na qualidade da água desse curso d'água.

Além do uso e ocupação, o regime climático exerce uma grande força sobre a qualidade dos recursos hídricos, pois disponibiliza no sistema fluvial, além da dissecação e transporte de sedimentos, a diluição e assimilação dos contaminantes naturais e/ou introduzidos pelo manejo antrópico.

No Brasil o regime de chuvas apresenta sazonalidade, com estação seca e chuvosa no ano de acordo com a localização geográfica (FIGUEROA e NOBRE, 1990), podendo comprometer os parâmetros físico-químicos e biológicos nos rios, tanto pela alteração da diluição e assimilação como também pela entrada de sedimentos com contaminantes ao sistema fluvial.

Um exemplo de ambiente com alto índice de área antropizada é a Bacia Hidrográfica do Córrego Moeda (BHCM), localizada em Três Lagoas, que possui $75 \%$ de sua área de propriedade da Fibria-MS Celulose Ltda.; sendo que $56 \%$ dessa área é ocupada por florestas de eucalipto clonadas, para a produção de celulose e papel. Nesta bacia existe outro agravante aos seus recursos hídricos, que é a instalação do Distrito Industrial do Moeda, criado pela Lei Municipal 2.427, de 2 de março de 2010, com a principal finalidade de definir pólo industrial para grande industrias, como é o caso da Fibria e da fábrica de fertilizantes e agroquímicos da Petrobras, a UFN III (Unidade de Fertilizantes Nitrogenados três Lagoas).

A preocupação com a instalação destas indústrias, bem como os impactos gerados pela expansão dos hortos de eucalipto e de grandes indústrias químicas, na qualidade e suas limitações de uso, fez com que esta pesquisa tivesse como objetivo principal, avaliar a influencia do uso e ocupação da terra, dos desvios climáticos na qualidade da água de bacias hidrográficas, elegendo como estudo de caso a Bacia Hidrográfica do Córrego Moeda, visando o estabelecimento de modelo de analise, visando subsidiar o planejamento ou ordenamento de bacias e à consecutiva redução dos impactos indesejáveis que afetam os mananciais hídricos disponíveis. 


\section{MATERIAL E MÉTODOS}

A BHCM possui área de $248,79 \mathrm{Km}^{2}$ e encontra-se entre as coordenadas geográficas de $20^{\circ} 50^{\prime} 00^{\prime \prime} \mathrm{S}$ e $21^{\circ} 01^{\prime} 10^{\prime \prime} \mathrm{S}$ e $52^{\circ} 01^{\prime} 08^{\prime \prime} \mathrm{O}$ e $51^{\circ} 44^{\prime} 55^{\prime \prime} \mathrm{O}$, como mostra a Figura 1. Localiza-se a sul da sede do município de Três Lagoas, a $26 \mathrm{~km}$ através da MS-395, em sentido a cidade vizinha de Brasilândia.

Figura 1: Mapa de Localização da Bacia Hidrográfica do Córrego Moeda, Três Lagoas/MS.

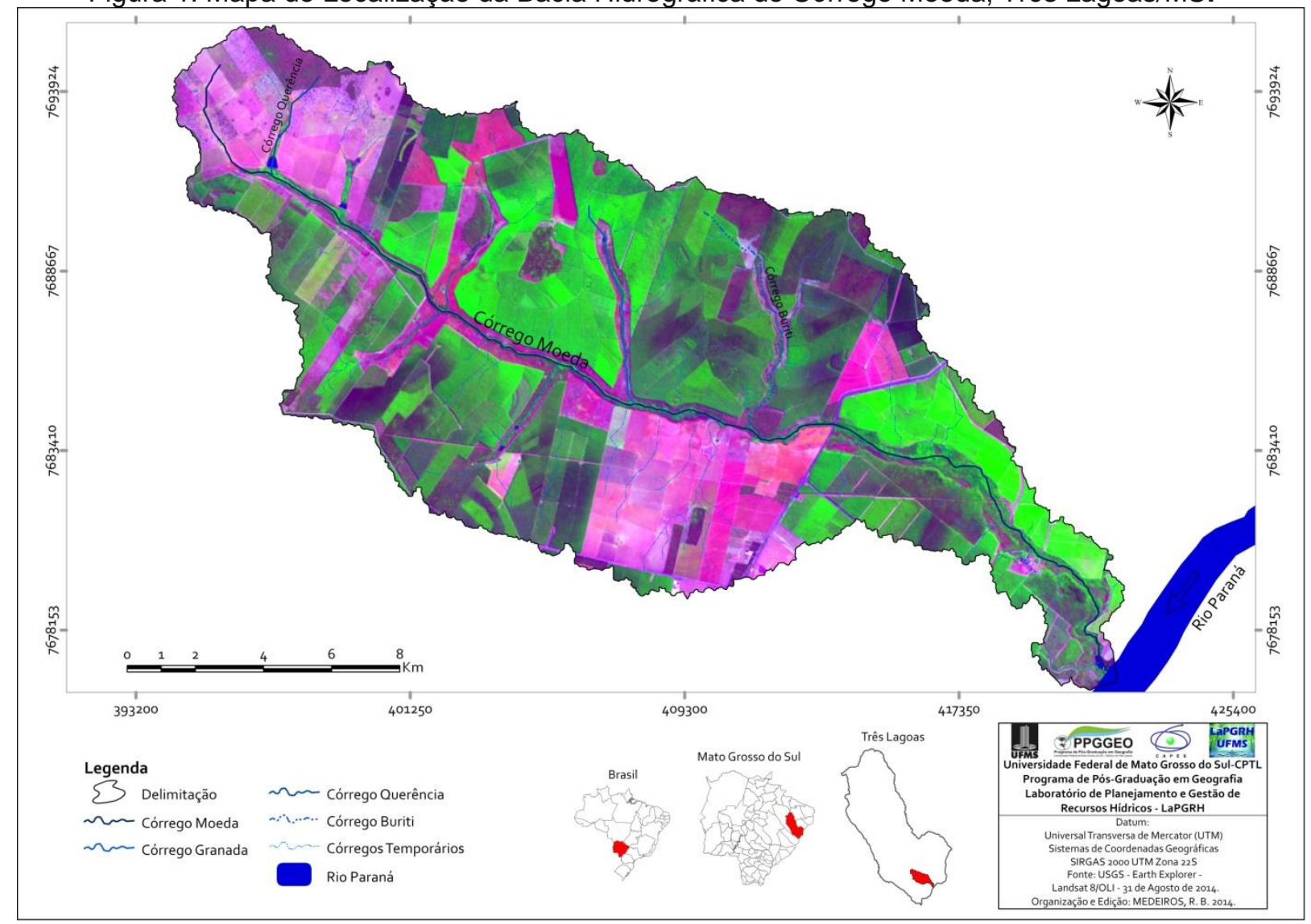

Os dados de precipitação foram obtidos de 1983 a 2012, junto à estação meteorológica da Fibria-MS Celulose Ltda.; localizada nas coordenadas $20^{\circ} 58^{\prime} 42$ "' $S$ e $51^{\circ} 46^{\prime} 30^{\prime \prime}$ W em seu viveiro de mudas, na BHCM. Esses dados são de extrema importância, pois o clima controla diretamente os processos erosivos.

Para a elaboração do mapa de uso e ocupação da Terra, foram necessárias informações sobre a área em 2012, através da Fibria-MS Celulose Ltda.; para posteriormente serem analisadas, através de imagens do Satélite Resource-Sat-1, órbita 326 e ponto $093 \mathrm{com}$ data de passagem em 05 de setembro de 2012, os locais exatos de determinadas ocupações e digitalizadas através do AutoCad 2012. 


\section{Periódica Eletranica

Sendo assim, foram separadas as classes em: Áreas Diversas, Hidrografia, Plantio Comercial de Eucalipto, Pastagem, Reserva Legal, Áreas de Preservação Permanente.

$\mathrm{Na}$ análise dos parâmetros para a verificação da qualidade das águas superficiais do Córrego Moeda, foram empregados equipamentos e métodos para a análise dos parâmetros: Oxigênio Dissolvido - OD, Condutividade - CE, Turbidez, $\mathrm{pH}$, Temperatura- $\mathrm{T}^{\circ} \mathrm{C}$; com exceção da turbidez, que o ensaio foi realizado em laboratório, os demais foram efetuados em campo.

O Oxigênio Dissolvido - OD é um gás solúvel em água, com concentrações variadas. Segundo Tchobanoglous e Schroeder (1985), devido à sua importância, o OD é amplamente utilizado como principal parâmetro da qualidade de água e serve para determinar o impacto de poluentes sobre corpos d'água, pois é um dos mais importantes fatores no desenvolvimento de qualquer planejamento na gestão de recursos hídricos, (SILVA e HERMES, 2004).

A Condutividade Elétrica - CE é a capacidade que a água possui de conduzir corrente elétrica. Este parâmetro está relacionado com a presença de íons dissolvidos na água, que são partículas carregadas eletricamente. Quanto maior for à quantidade de íons dissolvidos, maior será a condutividade elétrica da água.

O Potencial Hidrogeniônico - pH é quimicamente a medida de concentração de íons $\mathrm{H}+$ e íons $\mathrm{OH}$ presentes na solução, é uma das determinações de qualidade de água mais frequentemente executadas, apresentando a acidez ou a alcalinidade das águas, que podem ter origens em fatores naturais do terreno ou resultantes de poluentes dissolvidos na água, (CETESB, 1987).

A turbidez para Pinto (1998) é a alteração da penetração da luz provocada por partículas em suspensão, como bactérias, argilas e sílte ou fontes de poluição que lançam materiais finos e outras substâncias na água. Certamente, a presença dessas substâncias provoca a dispersão e a absorção da luz, dando à água aparência nebulosa, esteticamente indesejável e potencialmente perigosa.

As temperaturas, também outro parâmetro analisado, podem gerar camadas d'água com várias densidades, que em si já formam uma barreira física, impedindo que se misturem, e se a energia do vento não for suficiente para misturá-las, o calor não se distribui uniformemente, criando a condição de estabilidade térmica. 


\section{Periódica Eletrânica

A Tabela 1 e Quadro 1 apresentam a legislação do Conselho Nacional do Meio Ambiente (CONAMA), com os principais parâmetros usados no enquadramento de qualidade para águas superficiais e o enquadramento de uso das mesmas, foi utilizada a resolução 357 de 2005.

Tabela 1: Limites dos Parâmetros Analisados para Enquadramento nas Classes das Águas Doces no Brasil.

\begin{tabular}{|c|c|}
\hline Classes & Limites para o Enquadramento \\
\hline Especial & $\begin{array}{l}\text { Nas águas de classe especial deverão ser mantidas as condições naturais do } \\
\text { corpo de água. OD+10,0 mg/l; pH 6,0 a 9,0; Turbidez até } 20 \text { NTU; Condutividade } \\
\text { Elétrica até } 50 \text { um }\end{array}$ \\
\hline । & $\begin{array}{l}\text { OD } 10 \text { a } 6 \text { mg/l; pH 6,0 a 9,0; Turbidez } 20 \text { até } 40 \text { NTU; Condutividade Elétrica } 50 \\
\text { até } 75 \text { um. }\end{array}$ \\
\hline II & $\begin{array}{l}\text { OD } 6 \text { a } 5 \mathrm{mg} / \mathrm{l} ; \mathrm{pH} 6,0 \text { a 9,0; Turbidez } 40 \text { até } 70 \mathrm{NTU} \text {; Condutividade Elétrica } 75 \\
\text { até } 100 \mathrm{um} \text {. }\end{array}$ \\
\hline III & $\begin{array}{l}\text { OD } 5 \text { a } 4 \mathrm{mg} / \mathrm{l} ; \mathrm{pH} 6,0 \text { a 9,0; Turbidez } 70 \text { até } 100 \mathrm{NTU} \text {; Condutividade Elétrica } \\
100 \text { até } 150 \mathrm{um} \text {. }\end{array}$ \\
\hline IV & $\begin{array}{l}\text { OD - } 4 \text { mg/l; pH 6,0 a 9,0; Turbidez acima de } 100 \text { NTU; Condutividade Elétrica } \\
+150 \text { um. }\end{array}$ \\
\hline
\end{tabular}

Fonte: Pinto e Silva (2008) adaptado da Resolução n‥ 357/05 do CONAMA.

Quadro 1: Principais Classes de Limitações de Uso das Águas Doces no Brasil.

\begin{tabular}{|c|l|}
\hline Classes & \multicolumn{1}{|c|}{ Principais Usos } \\
\hline Especial & $\begin{array}{l}\text { Consumo humano com desinfecção; Preservação de equilíbrio natural das comunidades } \\
\text { aquáticas; Preservação dos ambientes aquáticos em unidades de conservação de } \\
\text { proteção integral. }\end{array}$ \\
\hline I & $\begin{array}{l}\text { Consumo humano, após tratamento simplificado; Proteção das comunidades aquáticas; } \\
\text { Recreação de contato primário (natação, esqui aquático e mergulho) Resolução } \\
\text { CONAMA n. 274, de 2000; Irrigação de hortaliças que são consumidas cruas e de frutas } \\
\text { que se desenvolvam rentes ao solo e que sejam ingeridas sem remoção de películas e à } \\
\text { proteção das comunidades aquáticas em Terras Indígenas. }\end{array}$ \\
\hline II & $\begin{array}{l}\text { Abastecimento para consumo humano, após tratamento convencional, à proteção das } \\
\text { comunidades aquáticas, à recreação de contato primário, tais como natação, esqui } \\
\text { aquático e mergulho, Resolução CONAMA n. 274, de 2000, à irrigação de hortaliças, } \\
\text { plantas frutíferas e de parques, jardins, campos de esporte e lazer, com os quais o } \\
\text { público possa vir a ter contato direto e à aqüicultura e à atividade de pesca. }\end{array}$ \\
\hline III & $\begin{array}{l}\text { Abastecimento para consumo humano, após tratamento convencional ou avançado, à } \\
\text { irrigação de culturas arbóreas, cerealíferas e forrageiras, à pesca amadora, à recreação } \\
\text { de contato secundário e à dessedentação de animais. }\end{array}$ \\
\hline IV & \begin{tabular}{l} 
Navegação e à harmonia paisagística \\
\hline
\end{tabular}
\end{tabular}

Fonte: Resolução noo. 357 do CONAMA de 17/03/2005.

Os pontos amostrais de monitoramento foram enumerados do ponto 1 até 0 ponto 11. Os pontos receberam o nome de estações e foram escolhidos previamente segundo critérios como: açudes, captação de água pela Fibria-MS Celulose Ltda.; confluência com outros córregos, foz de afluente e na foz do próprio Córrego Moeda sendo elas enumeradas ao entorno da bacia hidrográfica. 


\section{RESULTADOS E DISCUSSÃO}

Segundo Köppen, a área de estudo é classificada como Aw (tropical com verão chuvoso e inverno seco). A Tabela 2 demonstra os índices de pluviosidade média mensal, temperatura e respectivas porcentagens de chuvas para cada mês e estação.

$\mathrm{Na} \mathrm{BHCM}$, pode-se perceber através da Tabela 2, que as médias anuais de 1983 a 2012 e seu desvio em relação ao ano de 2012 mostram que apenas quatro meses ocorreram desvios positivos e que 2012 obtiveram precipitações inferiores a media das normais em $-119,75 \mathrm{~mm}$.

Tabela 2: Precipitação Normal, no ano de 2012 e Desvio, da BHCM, Três Lagoas,MS.

\begin{tabular}{cccccc}
\hline $\begin{array}{c}\text { Estações } \\
\text { do ano }\end{array}$ & Meses & Temperatura & $\begin{array}{c}\text { Normal de 1983 a } \\
\mathbf{2 0 1 2}\end{array}$ & Ano 2012 & Desvio (mm) \\
\hline \multirow{4}{*}{ Verão } & Janeiro & 25,9 & 235,5 & 191,78 & $-43,78$ \\
& Fevereiro & 26,4 & 195,2 & 106,43 & $-88,77$ \\
& Março & 26,1 & 171,3 & 87,88 & $-83,42$ \\
& Total Verão & & 602,0 & 386,09 & $-215,91$ \\
& Abril & 23,9 & 92,8 & 59,44 & $-33,36$ \\
Outono & Maio & 21,5 & 57,3 & 81,2 & $+23,9$ \\
& Junho & 19,7 & 18,9 & 219,46 & $+200,56$ \\
& Total Outono & & 169,0 & 360,1 & $+191,1$ \\
& Julho & 19,4 & 17,4 & 8,13 & $-9,27$ \\
Inverno & Agosto & 21,8 & 26,4 & 0,0 & $-26,4$ \\
& Setembro & 23,5 & 68,2 & 99,06 & $+30,86$ \\
& Total Inverno & & 112,0 & 107,19 & $-4,81$ \\
& Outubro & 25,2 & 101,5 & 13,46 & $-88,04$ \\
\multirow{5}{*}{ Primavera } & Novembro & 25,8 & 146,3 & 119,89 & $-26,41$ \\
& Dezembro & 25,9 & 190,1 & 210,82 & $+20,72$ \\
& Total Primavera & & 437,9 & 344,17 & $-93,73$ \\
\hline
\end{tabular}

Nota-se que o verão e a primavera abrangeram um total $78,73 \%$ de toda a precipitação ocorrida na BHCM. Já durante o outono, que abrange 12,79\% da precipitação total da bacia, mostra-se um começo de redução das precipitações, com o mês de abril já reduzindo para $92,80 \mathrm{~mm}$ de média. Após essa redução os meses seguintes (Maio e Junho) alcançaram precipitações reduzidas, com 57,30mm e $18,90 \mathrm{~mm}$ respectivamente.

O inverno é a estação mais seca dentre todas, pois só alcançou $8,48 \%$ da precipitação total, fazendo com que os meses de Julho se qualifiquem como o mês menos chuvoso e frio na média. Nota-se nesta estação, que setembro se estabelece 
como um período de transição, pois começa a elevar a temperatura e a pluviosidade é mais abundante do que nos outros meses do inverno.

De forma geral, o período chuvoso estende-se de Outubro a Março abrangendo, sobretudo a primavera e o verão. A estação mais fria e mais seca é o inverno onde as precipitações alcançam ao todo $112 \mathrm{~mm}$.

Nota-se que em apenas 4 meses do ano de 2012 ocorreu um acréscimo na quantidade de precipitação em relação à normal, tendo como o principal, o mês de Junho, onde choveu 200,56 mm a mais do que a normal, sendo um ano atípico, pois esse mês não é obtido grandes precipitações, ficando a normal em torno de 18,9 $\mathrm{mm}$. Outro fator considerado é a grande redução das precipitações no verão, onde todos os meses ocorreram redução, acarretando em 215,91 mm a menos que a normal.

No outono devido principalmente a esse mês de junho, ocorreu um aumento no desvio, totalizando $191,1 \mathrm{~mm}$ a mais que a normal. Já no inverno ocorreu uma pequena diminuição no ano de 2012 em relação à normal, com o mês de agosto apresentando $0,0 \mathrm{~mm}$ de precipitação, um mês de seca que ocasionou essa redução de $4,81 \mathrm{~mm}$ em relação à normal.

$\mathrm{Na}$ primavera, ocorreu uma redução das precipitações, com apenas dezembro obtendo um aumento, entretanto a estação obteve um desvio de 93,73 $\mathrm{mm}$ a menos que a normal. Percebe-se que a maioria dos meses obteve índices mais baixos de precipitação que a normal, fazendo com que em 2012 ocorra um desvio de 119,75 mm a menos do que a precipitação média anual.

Além dos dados de precipitação, as informações sobre o uso e ocupação da terra na BHCM se tornam importantes aliados para entender as influências destes elementos sobre seus recursos hídricos, subsidiando assim, ações e/ou sugestões para um melhor aproveitamento deste território.

A BHCM drena uma área de 26.839,15 ha, destes, em abril de 2012 , $14.934,10$ ha é ocupada com florestas de eucalipto, totalizando $56 \%$, a pecuária extensiva de corte e pastagens ocupam 19\% e as APPs e reservas legais $22 \%$, 0 restante é de áreas diversas e a própria área da Fibria-MS Celulose Ltda; Figura 4. 


\section{Periódica Eletrânica

Figura 2: Uso e Ocupação da Terra na Bacia Hidrográfica do Córrego Moeda.

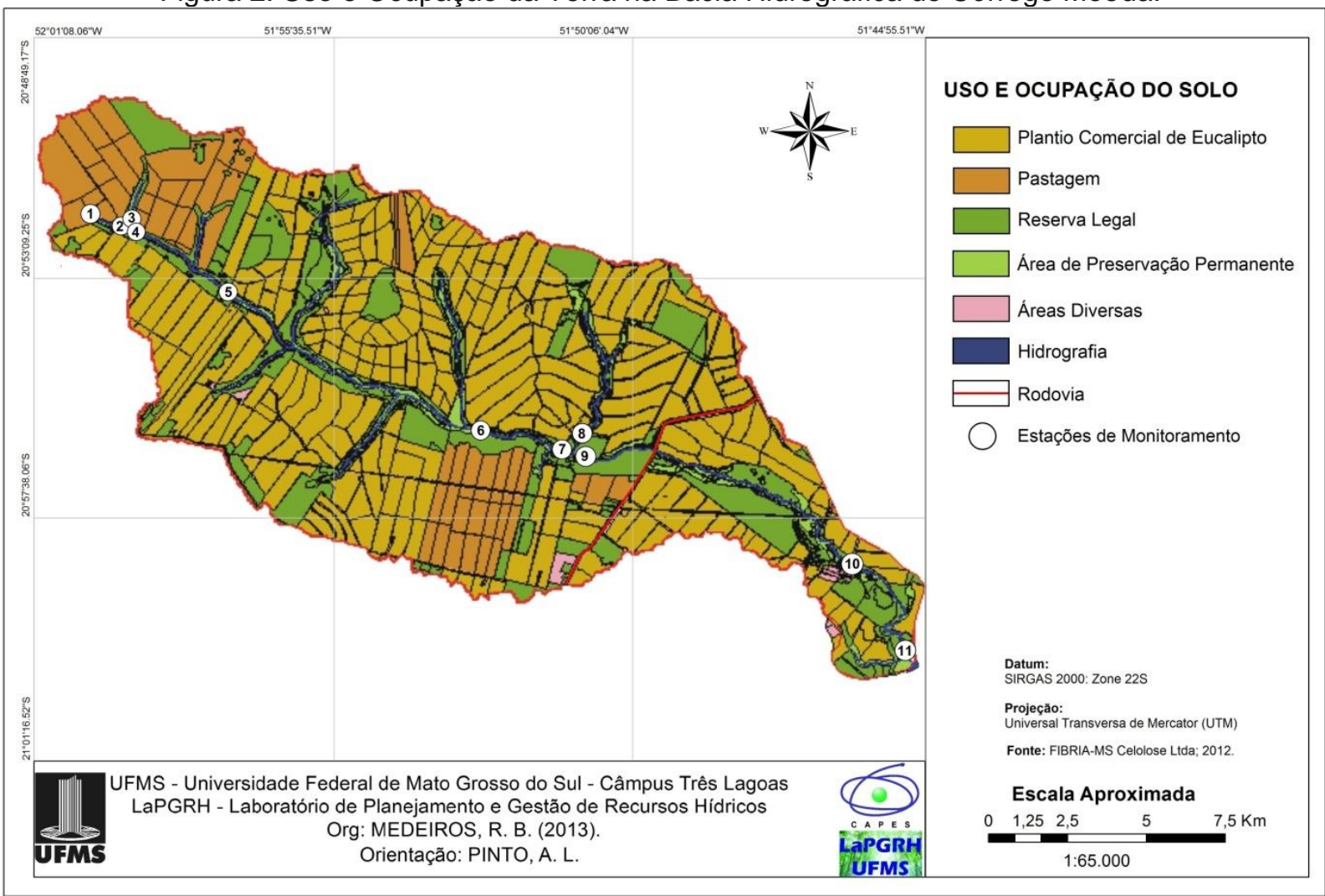

As matas ciliares encontram-se em sua grande maioria em estágio de regeneração, com exceção de manchas dispersas sobre tudo no alto curso na margem esquerda, fazenda Querência, médio curso próximo a foz do Córrego Buriti e no baixo curso, área da Fibria-MS Celulose Ltda; da ponte da BR 262 até a sua foz no rio Paraná.

Fazendas destinadas à pecuária extensiva de corte recobrem 19,08\% da área da bacia, com exceção da fazenda Querência em seu alto curso, as demais não se utilizam de curvas de nível e de práticas regulares de descompactação dos pastos e rodízio de campos.

Utilizando-se destas informações, buscou-se a análise dos dados de $\mathrm{pH}$, Oxigênio Dissolvido - OD, Condutividade - CE, Turbidez e as temperaturas da água e do ar, para correlacionar a qualidade das águas superficiais da BHCM.

Para facilitar o entendimento dos resultados dos exames de qualidade das águas superficiais da bacia do Córrego Moeda, foram geradas as Tabelas 3, 4, 5 e 6, que qualificam e enquadram os resultados por estação do ano, de 2012. E a Tabela 7 mostra o enquadramento médio das águas da BHCM, para cada ponto de monitoramento e para a bacia como um todo. 
Tabela 3: Parâmetros de Qualidade das Águas no Verão de 2012.

\begin{tabular}{cccccccc}
\hline Pontos & $\begin{array}{c}\text { CE } \\
\text { (um) }\end{array}$ & $\begin{array}{c}\text { OD } \\
(\mathbf{m g} / \mathbf{L})\end{array}$ & $\begin{array}{c}\text { Temp. } \\
\mathbf{A r}\left({ }^{\circ} \mathbf{C}\right)\end{array}$ & $\begin{array}{c}\text { Temp. } \\
\mathbf{H 2 O}\left({ }^{\circ} \mathbf{C}\right)\end{array}$ & pH & $\begin{array}{c}\text { Turbidez } \\
\text { NTU }\end{array}$ & $\begin{array}{c}\text { Classes de } \\
\text { Enquadamento }\end{array}$ \\
\hline 1 & 53,0 & 4,0 & 28,9 & 29,0 & 7,0 & 28.00 & III \\
2 & 19,0 & 8.1 & 26,7 & 24,7 & 6,7 & 9.85 & $\mid$ \\
3 & 22,0 & 8.2 & 27,1 & 26,1 & 6,8 & 5.30 & $\mid$ \\
4 & 22,0 & 5.7 & 29,9 & 27,8 & 7,6 & 7,16 & $\mid$ \\
5 & 17,0 & 7,6 & 30,8 & 23,4 & 7,1 & 10,10 & $\mid$ \\
6 & 17,0 & 7.7 & 35.6 & 28,7 & 7.5 & 8,74 & $\mid$ \\
7 & 17,0 & 7,9 & 35,7 & 25,1 & 7,4 & 8,00 & $\mid$ \\
8 & 25,0 & 1,7 & 30,8 & 25,6 & 7,1 & 35,20 & IV \\
9 & 16,0 & 8,4 & 32,7 & 25,1 & 7,6 & 8,72 & $\mid$ \\
10 & 16,0 & 8,9 & 32,5 & 24,1 & 7,2 & 8,00 & $\mid$ \\
11 & 36,0 & 2,8 & 30,2 & 31,4 & 7,7 & 8,00 & IV \\
\hline
\end{tabular}

Os pontos amostrais de monitoramento 8 e 11 enquadraram-se na classe IV, devido à reduzida concentrações de OD. O ponto 11 localiza-se na foz do Córrego Moeda no Rio Paraná, nesta estação obteve a menor concentração de OD. E 0 8, baixo curso do afluente da margem esquerda, o Córrego Buriti, que registrou a menor concentração de OD e maior índice de turbidez.

O ponto 1 de monitoramento enquadrou-se na classe III, contudo, com o OD no limite, pois menos que $4 \mathrm{mg} / \mathrm{L}$ passaria para a classe IV. Bem como, registrou a maior temperatura da água e condutividade elétrica e a segunda maior turbidez, o que justifica o reduzido OD. De forma geral, no verão a bacia foi enquadrada na classe II.

Tabela 4: Parâmetros de Qualidade das Águas no Outono de 2012.

\begin{tabular}{cccccccc}
\hline Pontos & $\begin{array}{c}\mathbf{C E} \\
(\mathbf{u m})\end{array}$ & $\begin{array}{c}\text { OD } \\
(\mathbf{m g} \mathbf{\text { L }})\end{array}$ & $\begin{array}{c}\text { Temp. } \\
\mathbf{A r}\left({ }^{\circ} \mathbf{C}\right)\end{array}$ & $\begin{array}{c}\text { Temp. } \\
\mathbf{H 2 O}\left({ }^{\circ} \mathbf{C}\right)\end{array}$ & $\mathbf{p H}$ & $\begin{array}{c}\text { Turbidez } \\
\text { NTU }\end{array}$ & $\begin{array}{c}\text { Classes de } \\
\text { Enquadramento }\end{array}$ \\
\hline 1 & 112,0 & 4,20 & 27,0 & 24,8 & 7,20 & 0,82 & $\mid \mathrm{II}$ \\
2 & 23,0 & 6,20 & 21,8 & 20,8 & 7,00 & 0,47 & $\mid$ \\
3 & 27,0 & 6,00 & 24,3 & 21,3 & 7,10 & 0,47 & || \\
4 & 23,0 & 7,30 & 27,6 & 21,0 & 7,90 & 0,42 & $\mid$ \\
5 & 19,0 & 7,80 & 28,3 & 20,7 & 7,10 & 0,41 & $\mid$ \\
6 & 18,0 & 7,50 & 29,4 & 21,5 & 7,00 & 0,27 & $\mid$ \\
7 & 20,0 & 10,50 & 30,7 & 21,2 & 6,90 & 0,31 & Especia| \\
8 & 19,0 & 1,80 & 24,6 & 20,8 & 7,20 & 0,73 & IV \\
9 & 21,0 & 4,30 & 28,3 & 22,9 & 7,00 & 0,30 & || \\
10 & 25,0 & 8,10 & 27,9 & 21,0 & 7,10 & 0,33 & $\mid$ \\
11 & 27,0 & 2,60 & 27,7 & 26,3 & 7,70 & 0,25 & |V \\
\hline
\end{tabular}

No outono, o pontos 8 e 11, continuam se enquadrando na classe IV, devido ainda as reduzidíssimas concentrações de OD, ficando novamente o ponto 8 , com OD abaixo de 2,00 mg/L, Tabela 4. 
O ponto 1 , manteve-se na classe III, com uma pequena melhora no OD, apesar da redução das precipitações, registrando agora $4,20 \mathrm{mg} / \mathrm{L}$, porém não suficiente para mudança de classe. Contudo a condutividade elétrica mais que dobrou passando a 112,0 um, mostrando a redução no poder de assimilação e diluição com a redução das precipitações.

Devido também à redução nas concentrações de $\mathrm{OD}$, houve uma queda na classe de enquadramento nos pontos 3 e 9 , mudando da classe I no verão, para a classe II no outono.

Um ponto que deve ser destacado é o ponto 7 que obteve 0 melhor enquadramento da bacia hidrográfica nesta estação, posicionado-se na classe Especial, devido principalmente ao aumento nas concentrações de OD, que chegou à 10,40 mg/L. De forma geral, apesar da redução das precipitações, em relação ao verão, a BHCM ainda enquadrando-se na classe II.

Tabela 5: Parâmetros de Qualidade das Águas no Inverno de 2012.

\begin{tabular}{cccccccc}
\hline Pontos & $\begin{array}{c}\mathbf{C E} \\
(\mathbf{u m})\end{array}$ & $\begin{array}{c}\text { OD } \\
(\mathbf{m g} / \mathbf{L})\end{array}$ & $\begin{array}{c}\text { Temp. } \\
\text { do Ar }\left({ }^{\circ} \mathbf{C}\right)\end{array}$ & $\begin{array}{c}\text { Temp. } \\
\text { da H2O } \\
\left({ }^{\circ} \mathbf{C}\right)\end{array}$ & pH & $\begin{array}{c}\text { Turbidez } \\
\text { NTU }\end{array}$ & $\begin{array}{c}\text { Classe de } \\
\text { Enquadramento }\end{array}$ \\
\hline 1 & 21,00 & 5,00 & 29,1 & 29,3 & 7,50 & 590,00 & $\mid \mathrm{V}$ \\
2 & 25,00 & 6,40 & 25,9 & 23,8 & 7,80 & 19,60 & $\mid$ \\
3 & 28,00 & 4,90 & 25,3 & 24,9 & 7,80 & 8,20 & || $\mid$ \\
4 & 26,00 & 6,80 & 27,4 & 23,6 & 7,90 & 13,50 & $\mid$ \\
5 & 15,00 & 5,90 & 30,9 & 21,0 & 7,80 & 8,65 & || \\
6 & 26,00 & 6,80 & 27,4 & 23,6 & 7,90 & 11,20 & $\mid$ \\
7 & 19,00 & 8,50 & 30,8 & 22,3 & 7,70 & 10,70 & $*$ \\
8 & $*$ & $*$ & $*$ & $*$ & $*$ & $*$ & $*$ \\
9 & 20,00 & 6,30 & 29,8 & 22,3 & 7,70 & 8,87 & $\mid$ \\
10 & 23,00 & 9,20 & 25,8 & 20,8 & 8,30 & 7,46 & $\mid$ \\
11 & 34,00 & 4,10 & 26,6 & 24,6 & 8,10 & 5,30 & || $\mid$ \\
\hline
\end{tabular}

${ }^{*}$ Canal Fluvial Seco.

No inverno com a menor precipitação do ano de 2012, o ponto 8 secou por completo, por essa razão não foi enquadrado em nenhuma classe. Já o ponto 11 , enquadrou-se na classe III, havendo assim uma melhora em relação à estação anterior, devido ao aumento na quantidade de OD concentrado na água, Tabela 5.

Foi o que aconteceu também como o ponto 3 , que passou da classe II para a classe III nessa estação, devido à redução do OD. Já o ponto 1 de monitoramento manteve-se na classe IV, mesmo com um ligeiro aumento nas concentrações de $\mathrm{OD}$, apontando $5 \mathrm{mg} / \mathrm{L}$, devido a piora na sua turbidez, gerada pelo pisoteio do gado neste ponto. 
Nesta estação o ponto 7 que obteve 0 melhor concentração de OD, enquadramento da bacia hidrográfica nesta estação, na classe Especial, devido principalmente ao aumento nas concentrações de OD, que chegou à 10,40 mg/L. De forma geral, o inverno foi a estação menos chuvosa entre todas as outras enquadrando a BHCM na classe II.

Tabela 6: Qualidade das Águas na Primavera de 2012.

\begin{tabular}{cccccccc}
\hline Pontos & $\begin{array}{c}\text { CE } \\
\text { (um) }\end{array}$ & $\begin{array}{c}\text { OD } \\
(\mathbf{m g} / \mathbf{l})\end{array}$ & $\begin{array}{c}\text { Temp. do } \\
\mathbf{A r}\left({ }^{\circ} \mathbf{C}\right)\end{array}$ & $\begin{array}{c}\text { Temp. da } \\
\mathbf{H 2 O}\left({ }^{\circ} \mathbf{C}\right)\end{array}$ & pH & $\begin{array}{c}\text { Turbidez } \\
\text { NTU }\end{array}$ & $\begin{array}{c}\text { Classe de } \\
\text { Enquadramento }\end{array}$ \\
\hline 1 & 348,00 & 1,40 & 27,4 & 27,3 & 7,2 & 734 & $\mid \mathrm{V}$ \\
2 & 30,00 & 6,90 & 26,2 & 23,7 & 7,1 & 21,5 & $\mid$ \\
3 & 30,00 & 6,10 & 27,6 & 26,4 & 7,1 & 11,5 & $\mid$ \\
4 & 30,00 & 7,30 & 26,1 & 25,0 & 7,0 & 7,87 & $\mid$ \\
5 & 31,00 & 5,40 & 25,8 & 23,9 & 7,1 & 10,4 & || \\
6 & 26,00 & 6,80 & 26,6 & 25,4 & 7,0 & 13,8 & $\mid$ \\
7 & 24,00 & 7,30 & 31,2 & 24,9 & 7,0 & 12,0 & $\mid$ \\
8 & $*$ & $*$ & $*$ & $*$ & $*$ & $*$ & $*$ \\
9 & 22,00 & 7,50 & 33,5 & 25 & 7,2 & 14,3 & $\mid$ \\
10 & 27,00 & 6,90 & 29,0 & 25,1 & 7,3 & 9,32 & $\mid$ \\
11 & 35,00 & 4,10 & 25,8 & 28,4 & 7,3 & 4,51 & || $\mid$ \\
\hline
\end{tabular}

${ }^{*}$ Canal Fluvial Seco.

$\mathrm{Na}$ primavera ocorreu um aumento da precipitação em relação à estação anterior, no ponto 8 não foi realizada a coleta, pois o curso d'água está seco, mesmo com uma maior precipitação, dando a entender que este trecho do córrego é intermitente e o ponto 11 continua se enquadrando na classe III, devido à manutenção da quantidade de OD concentrado na água, Tabela 6.

Já o ponto 3, que passou da classe III para a classe I nessa estação, devido principalmente ao aumento das concentrações de $\mathrm{OD}$, enquanto o ponto 1 de monitoramento passou da classe III para classe IV na primavera, apontando $5 \mathrm{mg} / \mathrm{L}$, o que o enquadrou nessa classe. De forma geral, a BHCM se enquadrou na classe II, conforme a Tabela 7 . 
Tabela 7: Enquadramento Estacional e Médio das Águas Superficiais em 2012.

\begin{tabular}{|c|c|c|c|c|c|}
\hline $\begin{array}{l}0 \\
\stackrel{0}{0} \\
0 \\
0\end{array}$ & $\begin{array}{c}\text { Classe de } \\
\text { Enquadramento } \\
\text { Verão } 2012 \\
\end{array}$ & $\begin{array}{c}\text { Classe de } \\
\text { Enquadramento } \\
\text { Outono } 2012 \\
\end{array}$ & $\begin{array}{c}\text { Classe de } \\
\text { Enquadramento } \\
\text { Inverno 2012 }\end{array}$ & $\begin{array}{c}\text { Classe de } \\
\text { Enquadramento } \\
\text { Primavera } 2012 \\
\end{array}$ & $\begin{array}{c}\text { Classe de } \\
\begin{array}{c}\text { Enquadramento } \\
\text { Médio }\end{array} \\
\end{array}$ \\
\hline 1 & III & III & III & IV & III \\
\hline 2 & I & I & I & | & I \\
\hline 3 & I & II & III & 1 & II \\
\hline 4 & II & I & I & I & I \\
\hline 5 & I & I & II & II & II \\
\hline 6 & I & | & I & I & I \\
\hline 7 & I & Especial & I & I & I \\
\hline 8 & IV & IV & * & * & IV \\
\hline 9 & | & ॥ & I & I & | \\
\hline 10 & I & I & I & I & I \\
\hline 11 & IV & IV & III & III & IV \\
\hline MÉDIA & $\overline{\|}$ & 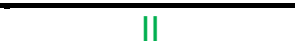 & 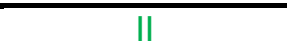 & 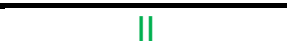 & 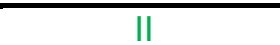 \\
\hline
\end{tabular}

${ }^{*}$ Canal Fluvial Seco.

Percebe-se na Tabela 07, que de forma geral, que a qualidade das águas monitoradas obtiveram grandes variações ao longo das estações do ano de 2012 , em média a BHCM se enquadrou na classe II, que preconiza pequenas limitações de uso para suas águas superficiais.

Os pontos de monitoramento 8,11 e 1, foram os que registraram um agravante na qualidades de suas águas, dentre eles os piores foram os pontos $8 \mathrm{e}$ 11, posicionaram na classe IV. O Ponto 8, localizado no baixo curso do Córrego Buriti, nas estações de verão e outono, ficou na classe IV e secou no inverno e na primavera de 2012. Já ponto 11, próximo à foz do Córrego Moeda no rio Paraná, obteve o enquadramento IV nas estações de verão e outono, e III, no inverno e na primavera. O ponto 1, localizado no açude construído no leito seco do alto curso do Córrego Moeda, apenas na primavera enquadrou-se na classe IV, as demais estações na classe III.

Contudo, as propriedades do alto curso utilizam, no ponto 1, a água para alimentação animal e humana sem tratamento e nos pontos 8 , ocorre o uso silvestre por parte de animais de pequenos até grandes porte, como as Antas. No ponto 11, além dos animais silvestres o rio é utilizado para a pesca amadora.

\section{CONCLUSÃO}

A influência do regime climático na qualidade das águas é bem definida, muito mais do que a influência do plantio de eucalipto. No verão chuvoso de 2012, a 


\section{Periádica Eletranica

redução das precipitações, com desvio negativo de 215,9 mm, propiciou pequena diluição e assimilação dos contaminantes, enquadrando suas águas, nesta estação, na classe II. Nota-se, porém que a precipitação do verão é pouco maior que a do outono, mas mesmo assim o enquadramento permaneceu na classe II, indicando um limite para esse processo de autodepuração.

$\mathrm{Na}$ primavera, mesmo com o aumento das precipitações, ficou abaixo da normal $93,8 \mathrm{~mm}$, manteve-se a bacia na classe II. Apenas os pontos monitoramento 1, 4, 6, 7, 9 e 10 apresentaram como classe I. Os pontos 3 e 5 foram enquadradas na classe II e apenas o ponto 1 foi enquadrada na classe III, enquanto os pontos 8 e 11 obtiveram as piores classificações médias da bacia, enquadradas assim, na classe IV, servindo apenas para navegação e harmonia paisagística.

Conclui-se, que o regime climático influencia diretamente a qualidade e enquadramento das águas da bacia, apesar de todas as estações a classificação media da bacia posicionar-se na classe II do CONAMA, porém pontualmente ela é marcante, principalmente no inverno e na primavera.

Estudos como este podem ajudar a manter a perenidade dos cursos fluviais e consecutivo potencial, para futuros usos humanos rurais e urbanos em bacias hidrográficas.

\section{REFERÊNCIAS}

BRASIL Conselho Nacional do Meio Ambiente - CONAMA Resolução 357/2005, Enquadramento dos Corpos Hídricos Superficiais no Brasil. Governo Federal, Brasilia. Publicada no DOU n 53, de 18 de março de 2005, Seção 1, páginas 58-63.

CETESB. Companhia de Tecnologia de Saneamento Básico. Guia de coleta e preservação de amostras de água. São Paulo, 1987: 150 p. (Séries guias)

CHRISTOFOLLETTI, A. Geomorfologia fluvial. São Paulo: Edgard Bluncher, 1981.

FIGUEROA, S.N.; NOBRE, C.A. Precipitation distribution over Central and Western tropical South America. Climanalise, 5: 36-45, 1990.

MATHEUS, C. E. et.al. BICRHEA - Centro de Recursos Hídricos e Ecologia Aplicada da USP. USP. São Carlos, 1995: 62p.

MORAES, A. J. de. Manual para avaliação da qualidade da água. São Paulo: RIMA, 2001.

PALMA - SILVA, G.M. Diagnóstico ambiental, qualidade da água e índice de depuração do Rio Corumbataí - SP; 1999. 155 f. Dissertação (Mestrado em Manejo Integrado de Recursos) - Centro de Estudos Ambientais, Universidade Estadual Paulista, Rio Claro, 1999.

PINTO, A. L.; SILVA, L. P. O oxigenio dissolvido como principal indicador de qualidade ede enquadramento dos corpos hídricos continentais: estudo de caso a bacia do rioSucuriú/MS. 
Anais...II Encontro de Ciências da Vida. Faculdade de Engenharia - UNESP, Campus de Ilha Solteira. Ilha Solteira (SP), 2008.

SILVA, A. de S; HERMES, L. C. Avaliação da qualidade das águas: manual prático. Brasília: EMBRAPA - Informação Tecnológica, 2004. 55p.

TUCHOBANOGLOUS, G.; SCHROEDER, E. D. Water quality - characteristics, modelling, modfication. Addison-Wesley Publ. Co., EUA, 1985. 